\title{
ANALISIS KETEBALAN LAPISAN PADA PENGECATAN BAJA KARBON RENDAH MENGGUNAKAN METODE RESPONS PERMUKAAN
}

\author{
Hayun Indra Nur Iman ${ }^{1, *}$, Mahros Darsin², Rahma Rei Sakura ${ }^{3}$ \\ ${ }^{1}$ Mahasiswa Jurusan Teknik Mesin, Fakultas teknik, Universitas Jember, Jl. Kalimantan 37, Jember, 68121 \\ ${ }^{2,3}$ Staf Pengajar Jurusan Teknik Mesin Fakultas Teknik, Universitas Jember, Jl. Kalimantan 37, Jember, 68121 \\ *E-mail: mahros.teknik@unej.ac.id
}

\begin{abstract}
ABSTRAK
Jumlah kendaraan bermotor mengalami peningkatan setiap tahunnya. Peningkatan ini diiringi dengan peningkatan jumlah kecelakaan yang terjadi. Kecelakaan yang terjadi berakibat kerusakan pada kendaraan bermotor sehingga diperlukan pengecatan ulang. Pengecatan merupakan suatu upaya yang dilakukan dengan mengaplikasikan cat dalam bentuk cair pada permukaan suatu objek guna membuat lapisan pada permukaan objek. Pengecatan berfungsi melindungi dan memperbagus tampilan suatu permukaan. Tujuan dari penelitian ini adalah untuk mengetahui pengaruh dari kombinasi parameter yang dapat menghasilkan nilai ketebalan maksimum. Desain eksperimen yang digunakan pada penelitian ini adalah metode respons permukaan dengan tiga parameter di mana masing-masing parameter memiliki tiga level. Parameter yang dipilih yaitu jarak penyemprotan $(110 \mathrm{~mm}, 130$ $\mathrm{mm}, 150 \mathrm{~mm})$, komposisi antara cat-thinner $(1: 1,6 ; 1: 1,4 ; 1: 1,2)$, dan tekanan $(3,5 ; 4,5 ; 5,5)$. Proses pengecatan dilakukan dengan bantuan paint test demonstrator. Hasil pengecatan dikeringkan pada oven yang selanjutnya dilakukan pengukuran menggunakan thickness gauge. Data hasil pengukuran diolah menggunakan bantuan software Minitab dan didapatkan persamaan penduga untuk ketebalan. Parameter dengan pengaruh terbesar pada penelitian ini yaitu jarak penyemprotan dengan nilai koefisien jarak sebesar 2,258. Pengecatan dengan nilai ratarata ketebalan tertinggi terjadi pada percobaan ke lima belas dengan nilai ketebalan sebesar $39.9 \mu \mathrm{m}$. Ketebalan tersebut didapatkan dengan variasi variabel jarak $130 \mathrm{~mm}$, komposisi cat-thinner 1:1,4 dan tekanan 4,5 bar.
\end{abstract}

Kata kunci: pengecatan; ketebalan; metode respons permukaan.

\section{ABSTRACT}

The number of vehicles has increased every year. This increase was accompanied by an increase in the number of accidents that occurred. Accidents that occur result in damage to vehicles so that repainting is needed. Painting is an effort made by applying paint in liquid form on the surface of an object to create a layer on the surface of the object. Painting serves to protect and improve the appearance of a surface. The purpose of this study is to determine the effect of a combination of parameters that can produce maximum thickness values. The experimental design used in this study is a surface response method with three parameters where each parameter has three levels. The parameters chosen were spraying distance (110 $\mathrm{mm}, 130 \mathrm{~mm}, 150 \mathrm{~mm})$, composition between paint-thinner $(1: 1.6 ; 1: 1.4 ; 1: 1,2)$, and pressure $(3,5 ; 4,5 ; 5.5)$. The painting process is carried out with the help of a paint test demonstrator. The painting results are dried in the oven and then measured using a thickness gauge. The measurement data is processed using the help of Minitab software and the estimator equation for thickness is obtained. The parameters with the greatest influence in this study are the distance of spraying with a distance coefficient of 2.258. Painting with the highest average value of thickness occurred in the fifteenth experiment with a thickness value of $39.9 \mu \mathrm{m}$. The thickness is obtained by variable variations of $130 \mathrm{~mm}$ distance, paint-thinner 1: 1.4 composition and 4.5 bar pressure.

Keywords: painting; thickness; response surface method 


\section{PENDAHULUAN}

Jumlah kendaraan bermotor selama periode 2013-2017 mengalami peningkatan rata-rata yang cukup tinggi yaitu 7,40 persen per tahun. Peningkatan jumlah kendaraan mengakibatkan terjadinya kepadatan arus lalu lintas. Kepadatan arus lalu lintas memungkinkan terjadinya kecelakaan. Kecelakaan kendaraan bermotor selama periode 2013-2017 mengalami kenaikan rata-rata 0,77 persen per tahun [1]. Kecelakaan dapat menyebabkan rusaknya cat pada bodi kendaraan bermotor sehingga perlu dilakukan pengecatan ulang.

Pengecatan merupakan suatu upaya yang dilakukan dengan mengaplikasikan cat dalam bentuk cair pada permukaan suatu objek guna membuat lapisan pada permukaan objek [2]. Objek produk yang dimaksud adalah bodi kendaraan bermotor. Bodi kendaraan bermotor terbuat dari baja, di mana baja dipilih karena relatif kuat dan mudah dibentuk. Lapisan pada permukaan kendaraan bermotor memiliki fungsi untuk melindungi bodi kendaraan dari korosi dan untuk memberikan tampilan yang bagus pada kendaraan. Penilaian terhadap kualitas lapisan cat yang bagus dapat dilakukan dengan melihat beberapa indikator salah satunya adalah ketebalan lapisan.

Ketebalan lapisan cat memiliki pengaruh yang besar terhadap perlindungan terhadap korosi. Ketebalan lapisan cat mempengaruhi laju korosi, semakin tipis lapisan cat maka semakin besar laju korosi [3]. Parameter tersebut di antaranya tekanan udara, jarak penyemprotan, komposisi mixing solvent, diameter nosel, jumlah pengulangan, kecepatan pengecatan, rasio distribusi lapisan, dan kekasaran permukaan [4].

Parameter pengecatan dapat diatur sedemikian rupa sehingga dapat menghasilkan hasil yang maksimal. Faktor jarak pengecatan dengan variasi $17 \mathrm{~cm}, 19 \mathrm{~cm}, 21 \mathrm{~cm}$ menghasilkan kualitas terbaik pada jarak $17 \mathrm{~cm}$ yang menghasilkan ketebalan $0.052 \mathrm{~mm}$ [5]. Faktor lain yang berpengaruh pada hasil ketebalan pengecatan adalah komposisi campuran cat. Variasi komposisi campuran cat $(1: 0,5 ; 1: 0,8$; 1:1) menghasilkan ketebalan tertinggi sebesar $0,140 \mathrm{~mm}$.
Penelitian dengan variasi tekanan, jarak spary gun dan komposisi cat-thinner belum pernah dilakukan secara bersamaan. Pengujian parameter secara bersamaan memerlukan suatu metode desain eksperimen. Metode desain eksperimen yang digunakan bertujuan untuk memperbaiki kualitas suatu produk, salah satu di antaranya ialah metode respons permukaan. Metode respons permukaan dipilih untuk melihat pengaruh beberapa variabel kuantitatif terhadap suatu variabel respons dan juga dapat menganalisa variabel respons tersebut [6].

\section{METODE PENELITIAN}

\subsection{Tahap Persiapan Benda Kerja}

Spesimen yang digunakan pada penelitian ini adalah material pelat baja St37. Meterial baja dipilih karena merupakan material yang sering digunakan pada bodi kendaraan bermotor. Spesimen yang digunakan untuk pengujian berukuran panjang $100 \mathrm{~mm}$ x lebar $50 \mathrm{~mm}$ dan tebal $1 \mathrm{~mm}$ sebanyak 45 lembar. Proses selanjutnya adalah pembersihan permukaan menggunakan ampelas. Cat yang digunakan pada penelitian ini adalah Cat primer epoxy (epoxy) \&Thinner polyurethane.

\subsection{Tahap Pengecatan}

Proses pengecatan dilakukan dengan bantuan paint test demonstrator. Alat ini berfungsi untuk menjaga kecepatan dan jarak pengecatan agar tidak berubah ketika pengecatan dilakukan. Alat yang perlu disiapkan selanjutnya yaitu spray gun dengan kapasitas tekanan 0,25-0,45 $\mathrm{MPa}$ dengan diameter nozzle 1,2 $\mathrm{mm}$. Kompressor dengan kapasitas tekanan sebesar $0,7 \mathrm{MPa}$ dan kapasitas tangki 25 liter. Tahap pertama yang harus dilakukan adalah menghubungkan spray gun dengan kompressor menggunakan selang. Proses pembersihan wajib dilakukan terlebih dahulu untuk menghilangkan kotoran. Pembersihan dilakukan dengan thinner yang dimasukkan pada tabung kemudian disemprotkan. Proses selanjutnya adalah mencampur cat dan thinner sesuai variasi yang telah ditentukan. Cat yang sudah dicampur dimasukkan ke dalam tabung spray gun. Spray gun kemudian diatur tegak lurus terhadap benda kerja atau $90^{\circ}$ dengan jarak sesuai urutan variasi yang ditentukan. Proses pengecatan dilakukan dilakukan sesuai dengan urutan nomor 
kombinasi yang sudah ditentukan pada desain eksperimen. Pengulangan yang dilakukan pada penelitian ini adalah sebanyak tiga kali. Proses pengeringan cat dilakukan dengan oven selama 30 menit pada suhu $60{ }^{\circ} \mathrm{C}$.

\subsection{Tahap Pengukuran}

Alat ukur ketebalan cat (Thickness Gauge) yang digunakan memiliki spesifikasi rentang pengukuran $0-1250 \mu \mathrm{m} / 0-50 \mathrm{mil}$ dengan akurasi $\pm 2.5 \mu \mathrm{m}$. proses pengukuran dilakukan dengan menempelkan sensor pada permukaan spesimen. Hasil pengukuran yang didapat dicatat pada tabel yang telah disiapkan.

\subsection{Tahap Pengolaan Data}

Keunggulan metode respons permukaan adalah dapat mengetahui hasil dan kombinasi variasi parameter yang optimal. Dalam eksperimen yang akan digunakan, metode pengambilan data dan kombinasi level berdasarkan rancangan Box Behnken Design. Box Behnken Design digunakan karena jumlah dari eksperimen yang dilakukan lebih sedikit sehingga, waktu eksperimen yang dibutuhkan singkat. Analisa data respons permukaan dilakukan menggunakan bantuan software
Minitab dan tingkat signifikansi yang digunakan pada penelitian ini ialah sebesar $\alpha=5 \%$.

\subsection{Rancangan Percobaan}

Parameter yang digunakan pada penelitian ini yaitu jarak penyemprotan, komposisi dan tekanan, di mana setiap parameter memiliki tiga level. Level yang digunakan ditunjukkan oleh tabel 1 .

Tabel 1. Level Faktor Pengujian

\begin{tabular}{cccc}
\hline Faktor & $\begin{array}{c}\text { Level } \\
\text { Bawah }\end{array}$ & $\begin{array}{c}\text { Level } \\
\text { Menengah }\end{array}$ & $\begin{array}{c}\text { Level } \\
\text { Atas }\end{array}$ \\
\hline Kode & -1 & 0 & 1 \\
\hline Komposisi & $1: 1,6$ & $1: 1,4$ & $1: 1,2$ \\
Tekanan & 3,5 & 4,5 & 5,5 \\
(bar) & & & \\
Jarak $(\mathrm{mm})$ & 110 & 130 & 150 \\
\hline
\end{tabular}

\section{HASIL DAN PEMBAHASAN}

Data hasil nilai pengujian nilai Thickness Gauge dapat dilihat pada Tabel 2. Data hasil pengujian ketebalan lapisan cat. Selanjutnya data hasil rata-rata ketebalan lapisan cat diolah menggunakan software Minitab 18.

Tabel 2. Data Hasil Pengujian Ketebalan Lapisan Cat

\begin{tabular}{cccccccccccc}
\hline \multirow{2}{*}{ No } & \multicolumn{3}{c}{ Level } & \multicolumn{4}{c}{ Variable Proses } & \multicolumn{3}{c}{ Ketebalan $(\mu \mathrm{m})$} & Rata- \\
\cline { 2 - 9 } & Jarak & Komposisi & Tekanan & Jarak & Komposisi & Tekanan & A & B & C & rata \\
\hline 1 & -1 & -1 & 0 & 110 & $1: 1,6$ & 4,5 & 38,9 & 35,9 & 38,3 & 37,7 \\
2 & 1 & -1 & 0 & 150 & $1: 1,6$ & 4,5 & 37,7 & 35,2 & 34,5 & 35,8 \\
3 & -1 & 1 & 0 & 110 & $1: 1,2$ & 4,5 & 39,9 & 35,2 & 44,3 & 39,8 \\
4 & 1 & 1 & 0 & 150 & $1: 1,2$ & 4,5 & 31,6 & 35,3 & 30,6 & 32,5 \\
5 & -1 & 0 & -1 & 110 & $1: 1,4$ & 3,5 & 37,2 & 31,3 & 26,9 & 31,8 \\
6 & 1 & 0 & 1 & 150 & $1: 1,4$ & 3,5 & 24,1 & 32,5 & 29,5 & 28,7 \\
7 & -1 & 0 & -1 & 110 & $1: 1,4$ & 5,5 & 31,8 & 44,2 & 27,5 & 34,5 \\
8 & 1 & 0 & 1 & 150 & $1: 1,4$ & 5,5 & 31 & 31,3 & 23,8 & 28,7 \\
9 & 0 & -1 & -1 & 130 & $1: 1,6$ & 3,5 & 31,2 & 46,9 & 27,5 & 35,2 \\
10 & 0 & -1 & 1 & 130 & $1: 1,2$ & 3,5 & 28,3 & 24 & 33,8 & 28,7 \\
11 & 0 & 1 & -1 & 130 & $1: 1,6$ & 5,5 & 24,5 & 33,6 & 32,8 & 30,3 \\
12 & 0 & 1 & 1 & 130 & $1: 1,2$ & 5,5 & 30,9 & 44,5 & 20,3 & 31,9 \\
13 & 0 & 0 & 0 & 130 & $1: 1,4$ & 4,5 & 24,9 & 57,5 & 26,8 & 36,4 \\
14 & 0 & 0 & 0 & 130 & $1: 1,4$ & 4,5 & 36,2 & 43,6 & 29,7 & 36,5 \\
15 & 0 & 0 & 0 & 130 & $1: 1,4$ & 4,5 & 31,2 & 48,7 & 39,8 & 39,9 \\
\hline
\end{tabular}

\subsection{Analisis Data Ketebalan Lapisan Cat}

Langkah-langkah yang dilakukan untuk menganalisis data ketebalan lapisan cat yaitu dengan melakukan (i) pembentukan model, (ii) pengujian kesesuain model, dan (iii) pengujian residual. Pembentukan model merupakan hasil dari data percobaan yang telah diolah menggunakan Minitab 18 dan hasil pengolahan data yang didapatkan disebut "estimated regression coefficient for thickness".

Kemudian dibentuk sebuah model persamaan ketebalan yang diperoleh dari pengolahan data menggunakan Minitab 18. Selanjutnya langkah yang perlu dilakukan yaitu pengujian 
kesesuaian model. Pengujian kesesuaian model ini terdiri dari beberapa pengujian yaitu pengujian (i) lack of fit, (ii) pengujian parameter serentak, dan (iii) pengujian $R^{2}$. Adapun langkah terakhir yang harus dilakukan yaitu pengujian residual yang pula terdiri dari (i) pengujian identik, (ii) pengujian independen, dan (iii) pengujian distribusi normal.

\subsection{Pembentukan Model}

Pengolahan data yang dilakukan menggunakan software Minitab menghasilkan sebuah nilai koefisien penduga seperti yang ditunjukkan pada Tabel 3 Koefisien regresii model penduga ketebalan lapisan cat.

Tabel 3 menunjukkan hasil taksiran parameter model untuk ketebalan lapisan cat. Berdasarkan nilai koefisien yang ditunjukkan pada Tabel 3 didapatkan model persamaan ketebalan lapisan cat sebagai berikut.

$$
\begin{aligned}
Y_{k}=37,6-2, & 258 X_{1}-0,762 X_{2} \\
& +0,121 X_{3}-0,871 X_{1}^{2} \\
& -0,279 X_{2}^{2}-5,796 X_{3}^{2} \\
& -1.35 X_{1} X_{2} \\
& -0,683 X_{1} X_{3} \\
& +2,025 X_{2} X_{3}
\end{aligned}
$$

\begin{tabular}{|c|c|c|c|c|}
\hline Term & Coef & SE Coef & T-Value & P-Value \\
\hline Constant & 37,6 & 0,896 & 41,95 & 0 \\
\hline Distance $\left(\mathrm{X}_{1}\right)$ & $-2,258$ & 0,549 & $-4,11$ & 0,009 \\
\hline Compotition $\left(\mathrm{X}_{2}\right)$ & $-0,762$ & 0,549 & $-1,39$ & 0,223 \\
\hline Pressure $\left(\mathrm{X}_{3}\right)$ & 0,121 & 0,549 & 0,22 & 0,834 \\
\hline Distance*Distance $\left(\mathrm{X}_{1}\right) *\left(\mathrm{X}_{1}\right)$ & $-0,871$ & 0,808 & $-1,08$ & 0,33 \\
\hline Compotition*Compotition $\left(\mathrm{X}_{2}\right) *\left(\mathrm{X}_{2}\right)$ & $-0,279$ & 0,808 & $-0,35$ & 0,744 \\
\hline Pressure*Pressure $\left(\mathrm{X}_{3}\right) *\left(\mathrm{X}_{3}\right)$ & $-5,796$ & 0,808 & $-7,17$ & 0,001 \\
\hline Distance*Compotition $\left(\mathrm{X}_{1}\right) *\left(\mathrm{X}_{2}\right)$ & $-1,35$ & 0,776 & $-1,74$ & 0,142 \\
\hline Distance*Pressure $\left(\mathrm{X}_{1}\right) *\left(\mathrm{X}_{3}\right)$ & $-0,683$ & 0,776 & $-0,88$ & 0,419 \\
\hline Compotition*Pressure $\left(\mathrm{X}_{2}\right) *\left(\mathrm{X}_{3}\right)$ & 2,025 & 0,776 & 2,61 & 0,048 \\
\hline $\begin{array}{c}\mathrm{S} \\
1,55233 \\
\end{array}$ & $\begin{array}{c}\text { R-sq } \\
94,21 \%\end{array}$ & $\begin{array}{c}\text { R-sc } \\
83,\end{array}$ & dj) & $\begin{array}{c}\text { R-sq(pred) } \\
59,81 \%\end{array}$ \\
\hline
\end{tabular}

Tabel 3. Koefisien Regresi Model Penduga

\subsection{Pengujian Kesesuaian Model}

Untuk mengetahui kesesuaian model persamaan ketebalan, maka dilakukan pengujian sebagai berikut:

\section{a. Uji lack of fit}

Dalam menentukan ketetapan model diperlukan uji lack of fit. Pengujian lack of fit bertujuan untuk mengetahui kesesuaian model yang diinginkan. Hipotesis yang digunakan pada uji lack of fit adalah sebagai berikut:

$$
\begin{aligned}
& \mathrm{H}_{0}=\text { tidak ada lack of fit dalam model } \\
& \mathrm{H}_{1}=\text { ada lack of fit dalam model }
\end{aligned}
$$

Daerah penolakan pada uji lack of fit ini adalah hipotesis awal akan ditolak apabila p-value kurang dari $\alpha$. Besar nilai $\alpha$ pada penelitian ini adalah 5\%. Tabel 4 menunjukkan nilai $p$-value dari lack of fit adalah 0,801 yang berarti nilai ini lebih besar dari nilai $\alpha=0,05$. Dengan demikian dapat disimpulkan bahwa model tidak ada lack of fit atau model yang diperoleh telah sesuai.

Tabel 4. Analysis of Variance

\begin{tabular}{lccccc}
\hline \multicolumn{1}{c}{ Source } & DF & Adj Sum Square & Adj Mean Square & F-Value & P-Value \\
\hline Model & 9 & 195,976 & 21,775 & 9,04 & 0,013 \\
Linear & 3 & 45,569 & 15,19 & 6,3 & 0,038 \\
\hline
\end{tabular}




\begin{tabular}{lccccc}
\hline Square & 3 & 124,847 & 41,616 & 17,27 & 0,005 \\
2-Way Interaction & 3 & 25,56 & 8,52 & 3,54 & 0,104 \\
Error & 5 & 12,049 & 2,41 & & \\
Lack-of-Fit & 3 & 4,109 & 1,37 & 0,34 & 0,801 \\
Pure Error & 2 & 7,94 & 3,97 & & \\
Total & 14 & 208,024 & & & \\
\hline
\end{tabular}

\section{b. Uji Parameter Serentak}

Hipotesis yang digunakan pada pengujian parameter serentak adalah sebagai berikut:

$\mathrm{H}_{0}: \square_{1}=\square_{2}=\ldots . .=\square_{\mathrm{k}}=0$

$\mathrm{H}_{1}$ : minimal ada satu $\square_{\mathrm{j}} \neq 0 ; \mathrm{j}=1,2, \ldots, \mathrm{k}$

Pengujian parameter serentak dilakukan analisis terhadap p-value. Terdapat dua regresi yang harus diperiksa, yaitu linier $\left(\square_{1}\right)$ dan kuadratik $(\square 2)$. Nilai $p$-value untuk regresi linier dan regresi kuadratik yang ditunjukkan Tabel 3 sebesar 0,038 dan 0,05 . Nilai ini lebih kecil dari nilai $\alpha$ sehingga didapatkan kesimpulan bahwa secara keseluruhan model kombinasi linier dan kuadratis dalam penelitian memberikan kontribusi yang nyata terhadap model.

\section{c. Pengujian Koefisien Determinasi $\left(\mathrm{R}^{2}\right)$}

Nilai koefisien determinasi terletak di antara $0<\mathrm{R}^{2}<1$. Semakin besar nilai $\mathrm{R} 2$ maka semakin besar pula pengaruh variabel $\mathrm{X}$ terhadap variabel $Y$. Nilai koefisien determinasi diharapkan bernilai mendekati 1 untuk mendapatkan model yang baik. Berdasarkan Tabel 3 nilai R2 adalah 94,20\% mendekati 1 sehingga variasi dari respons tersebut dapat dijelaskan oleh model regresi yang terbentuk.

\subsection{Pengujian Residual}

Pengujian residual dilakukan untuk mengetahui apakah residual memenuhi asumsi normally and independently distributed. Pengujian residual terdiri dari uji identik, uji independen, dan uji distribusi normal. Berikut ini adalah pengujian yang dilakukan pada pengujian residual.

\section{a. Uji Identik}

Pada Gambar 1 dapat dilihat bahwa plot residual versus fitted values untuk residualnya tersebar secara acak di sekitar harga nol dan tidak membentuk suatu pola tertentu. Sehingga dapat disimpulkan bahwa asumsi bersifat identik.

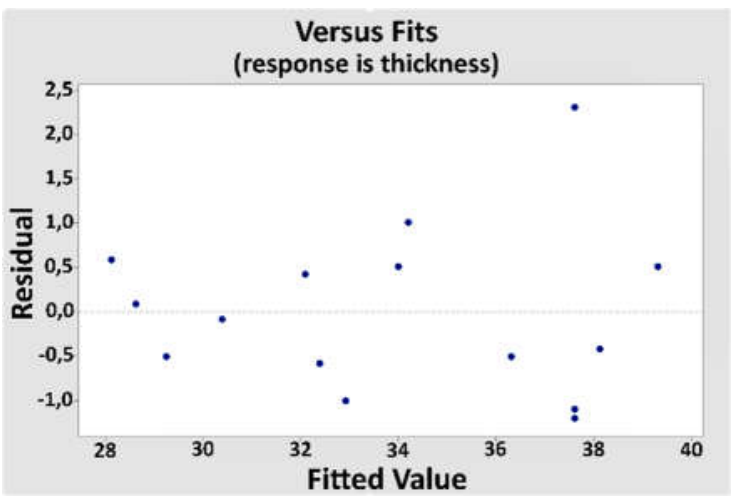

Gambar 1. Plot residual versus fitted values

\section{b. Uji Independen}

Plot autocorelation function (AFC) pada Gambar 2 menyatakan bahwa semua korelasi berada pada interval $\pm 0,516$, dengan jumlah pengamatan (n) sebanyak lima belas. Hal ini menunjukkan bahwa tidak ada korelasi antar pengamatan yang berarti pengamatan yang dilakukan secara independen terpenuhi.

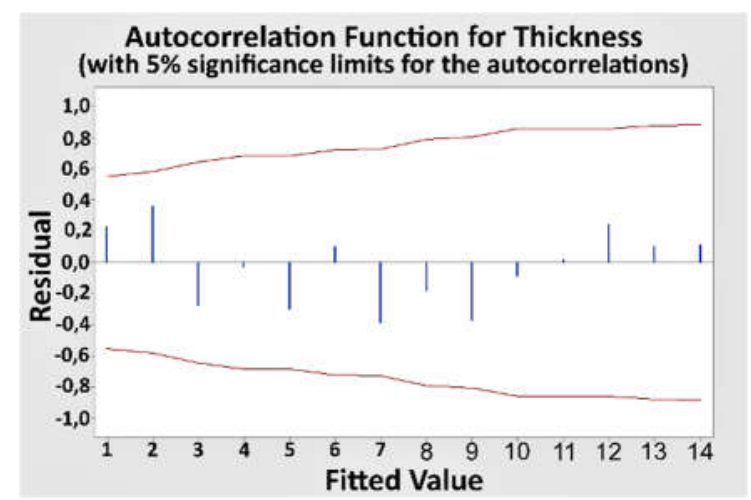

Gambar 2. Plot autocorelation function

\section{c. Uji Distribusi Normal}

Asumsi terakhir yaitu residual harus berdistribusi normal. Pemeriksaan asumsi distribusi normal dilakukan dengan melihat plot probabilitasnya. Gambar 3 menunjukkan bahwa plot mendekati garis lurus, sehingga dapat dikatakan bahwa residual berdistribusi normal. 
Selain itu pemeriksaan dapat dilakukan dengan hipotesis sebagai berikut:

$\mathrm{H}_{0}$ : residual berdistribusi normal

$\mathrm{H}_{1}$ : residual tidak berdistribusi normal

Terima $\mathrm{H}_{0}$ apabila $p$-value $>\alpha$

Nilai p-value pada untuk asumsi distribusi normal adalah 0,150 lebih besar dari nilai $\alpha=0,05$, sehingga diputuskan untuk gagal menolak $\mathrm{H}_{0}$ yang berarti residual berdistribusi normal. Nilai p-value dapat dilihat pada Gambar 3.

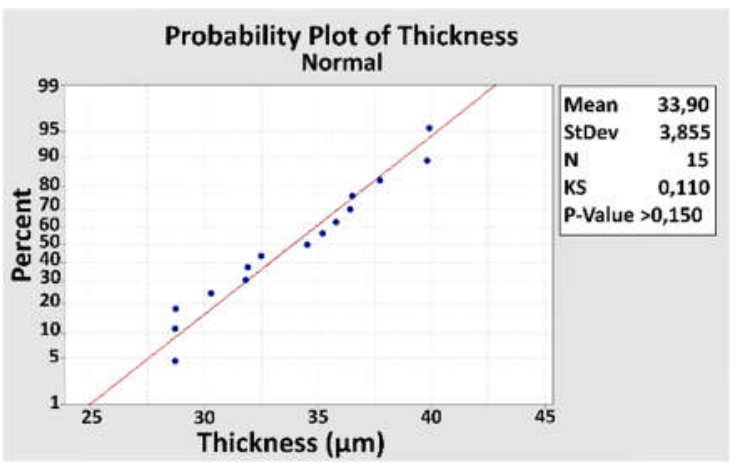

Gambar 3. Plot normal probability

\subsection{Analisis Contour Response Surface}

Setelah meakukan pengujian residual dan pengujian model, maka dilanjutkan analisis contour dan surface plot. Gambar di bawah ini menunjukkan hubungan antara ketebalan dengan variabel-variabel proses yang berpengaruh. Variabel yang berpengaruh terhadap ketebalan di antaranya jarak, komposisi dan tekanan. Analisis contour dan plot berikut ini menunjukkan hubungan antara respons ketebalan dengan dua variabel proses sedangkan variabel proses yang lain pada level menengah.

Gambar 4 menampilkan bahwa ketebalan yang tercapai pada komposisi di antara level 1:1,6 sampai 1:1,2 dan jarak berada pada level 110 sampai 150 dengan tekanan konstan 4,5 bar. Parameter proses tersebut menghasilkan ketebalan $32 \mu \mathrm{m}$ sampai $39 \mu \mathrm{m}$. Ketebalan dengan nilai tertinggi didapatkan pada komposisi 1:1,4 - 1:1,2 dan pada jarak $110 \mathrm{~mm}$. Nilai ketebalan tertinggi ditunjukkan oleh warna hijau tua, sedangkan nilai ketebalan terendah ditunjukkan oleh warna biru tua.

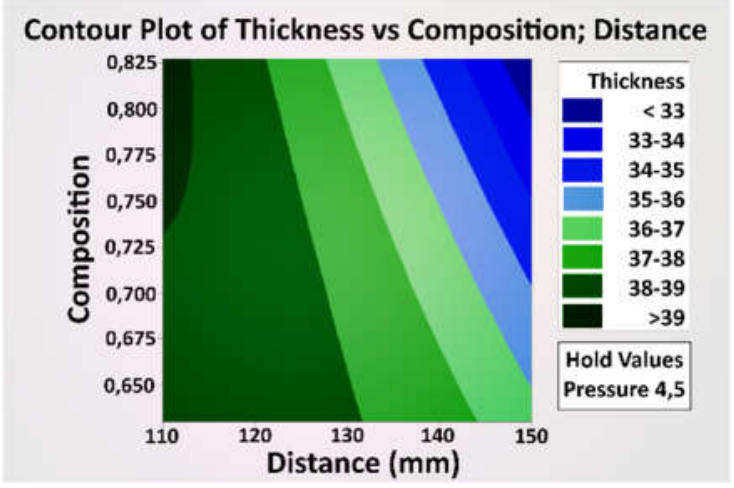

Gambar 4. Contour plot komposisi; jarak terhadap ketebalan pada tekanan 4,5 bar

Gambar 5 menampilkan bahwa ketebalan yang tercapai pada tekanan di antara level 3,5 sampai 5,5 dan jarak berada pada level 110 sampai 150 dengan komposisi konstan 1:1,4. Parameter proses tersebut menghasilkan ketebalan $28 \mu \mathrm{m}$ sampai $38 \mu \mathrm{m}$. Ketebalan dengan nilai tertinggi didapatkan pada tekanan 4-5 bar dan pada jarak 110-130 mm. Nilai ketebalan tertinggi ditunjukkan oleh warna hijau tua, sedangkan nilai ketebalan terendah ditunjukkan oleh warna biru tua.

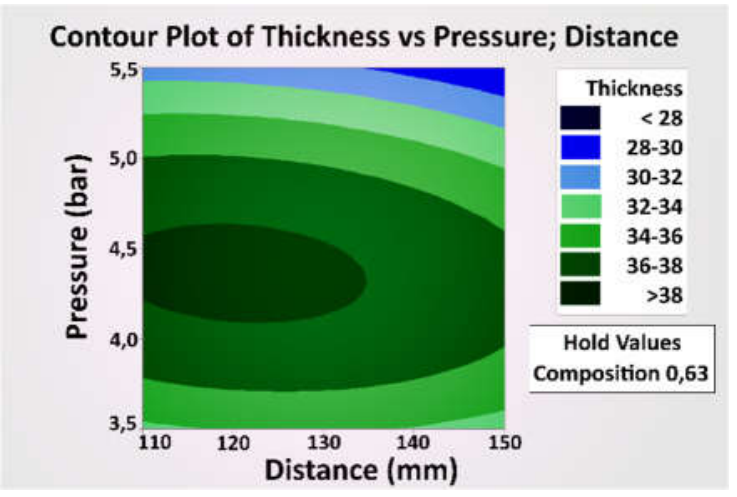

Gambar 5. Contour plot tekanan; Jarak terhadap ketebalan pada komposisi 1:1,6

Gambar 6 menampilkan bahwa ketebalan akan tercapai pada komposisi yang berada di antara level 1:1,6 sampai 1:1,2 dan tekanan berada pada level 3,5 sampai 5,5 dengan jarak konstan $110 \mathrm{~mm}$. Parameter proses tersebut menghasilkan ketebalan $32 \mu \mathrm{m}$ sampai $38 \mu \mathrm{m}$. Ketebalan dengan hasil tertinggi didapatkan pada tekanan 4-5 bar. 


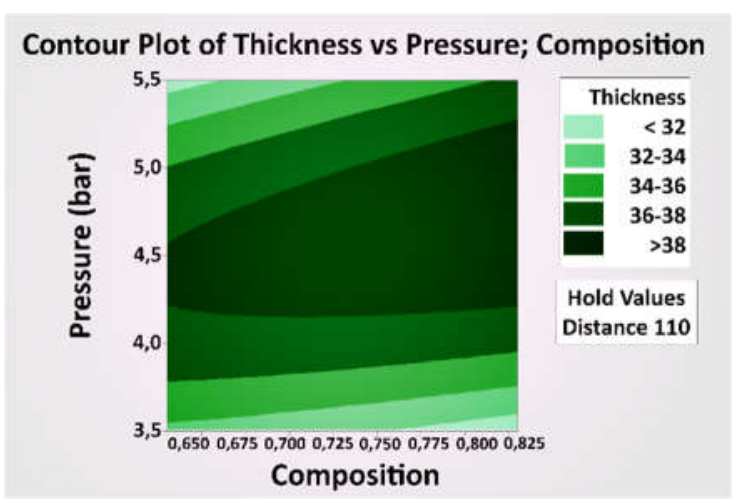

Gambar 6. Contour plot tekanan; Komposisi terhadap ketebalan pada jarak $130 \mathrm{~mm}$

\subsection{Optimasi Respons}

Kombinasi level-level variabel proses dapat menghasilkan respons optimum (target, minimum, dan maksimum) dapat dicari menggunakan metode respons permukaan dengan pendekatan fungsi desirability. Pendekatan fungsi desirability digunakan untuk mencari nilai kombinasi variabel proses jarak penyemprotan, komposisi dan tekanan agar mendapatkan ketebalan lapisan cat yang optimum (maximum). Hasil optimasi yang diperoleh dari kombinasi variabel proses menghasilkan respons optimum (maximum) yaitu dengan jarak penyemprotan $110 \mathrm{~mm}$, perbandingan komposisi 1:1,2 dan tekanan 4,75 bar sehingga menghasilkan ketebalan lapisan cat sebesar $39,6 \mu \mathrm{m}$. Seperti yang ditunjukkan pada Gambar 7.

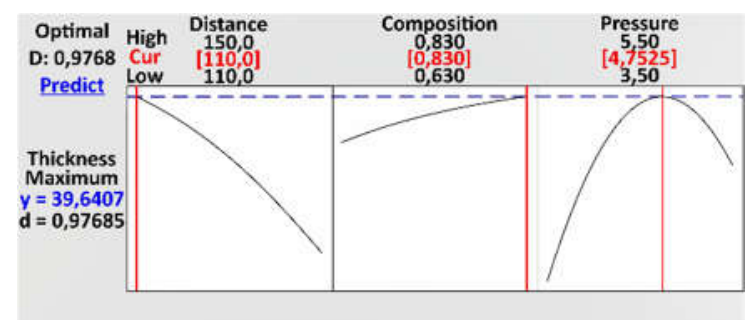

Gambar 7. Grafik kombinasi variabel proses dengan respons optimum

\subsection{Pembahasan}

Berdasarkan Tabel 3 diketahui variabelvariabel proses mempunyai pengaruh yang signifikan terhadap ketebalan hasil pengecatan. Variabel jarak memiliki pengaruh terbesar terhadap ketebalan dibandingkan variabel proses yang lain, dibuktikan dengan nilai koefisien $\left(\mathrm{X}_{1}\right)$ jarak yaitu 2,258. Koefisien jarak memiliki harga negatif yang menunjukkan bahwa jarak mempunyai pengaruh berbanding terbalik terhadap hasil ketebalan lapisan cat. Semakin besar nilai jarak, maka nilai ketebalan yang diperoleh akan semakin kecil. Pengaruh jarak telah ditunjukkan pada Gambar 4 dan Gambar 5 di mana semakin jauh jarak yang digunakan hasil ketebalan yang didapatkan semakin tipis. Kemungkinan penyebabnya adalah jarak yang semakin jauh mengakibatkan semprotan tidak fokus dan cat yang menempel pada permukaan lebih sedikit.

Koefisien komposisi memiliki harga negatif yang menunjukkan bahwa komposisi mempunyai pengaruh berbanding terbalik terhadap ketebalan lapisan cat. Pengaruh komposisi telah ditunjukkan pada Gambar 4 dan Gambar 6 yakni semakin besar jumlah thinner yang digunakan dalam campuran, maka nilai ketebalan yang diperoleh akan semakin kecil. Jumlah thinner yang besar mengakibatkan cat akan menjadi encer dan menjadikan cat yang menempel pada permukaan sedikit sebab thinner dalam komposisi akan menguap setelah proses pengecatan dilakukan. Thinner akan menguap ketika sampai pada permukaan karena pengaruh lingkungan.

Koefisien tekanan memiliki harga positif yang menunjukkan bahwa tekanan mempunyai pengaruh berbanding lurus terhadap respons. Semakin besar nilai tekanan, maka nilai ketebalan yang diperoleh akan semakin besar. Tekanan mempengaruhi jumlah cat yang keluar dari nozzle, sehingga ketebalan cat yang terbentuk semakin tebal. Pengaruh tekanan telah ditunjukkan pada Gambar 5 dan Gambar 6 ketika tidak selalu tekanan yang besar menghasilkan ketebalan yang besar. Penelitian ini mendapatkan hasil ketebalan dengan nilai tertinggi pada tekanan 4-5 bar. Hal ini dikarenakan tekanan yang terlalu besar berakibat tidak fokusnya proses penyemprotan sehingga cat yang menempel pada permukaan tidak terlalu banyak. Tekanan yang terlalu kecil mengakibatkan proses pengabutan tidak berjalan maksimal sehingga rata-rata ukuran droplet besar dan cat yang menumpuk pada permukaan menetes sehingga cat yang menempel pada permukaan tersisa sedikit.

Percobaan yang menghasilkan nilai rata-rata ketebalan tertinggi terjadi pada percobaan ke 
lima belas dengan nilai ketebalan sebesar $39.9 \mu \mathrm{m}$. Ketebalan tersebut didapatkan dengan variasi variabel jarak $130 \mathrm{~mm}$, komposisi catthinner 1:1,4 dan tekanan 4,5 bar. Percobaan yang menghasilkan nilai rata-rata ketebalan terendah terjadi pada tiga percobaan, yaitu pada percobaan keenam kedelapan dan kesepuluh dengan nilai ketebalan $28,7 \mu \mathrm{m}$.

\section{KESIMPULAN}

Setelah melakukan penelitian, maka dapat di tarik kesimpulan sebagai berikut: Jarak penyemprotan memiliki pengaruh terbesar terhadap ketebalan hasil pelapisan dibandingkan variabel lainnya dengan bukti nilai koefisien jarak sebesar 2,258. Nilai koefisien jarak ini bernilai negatif yang berarti bahwa semakin dekat jarak pengecatan yang dilakukan, maka ketebalan lapisan cat yang diperoleh akan semakin tebal. Hasil percobaan yang menghasilkan nilai rata-rata ketebalan tertinggi yaitu $39.9 \mu \mathrm{m}$ terletak pada percobaan kelima belas dengan variasi variabel jarak 130mm, tekanan 4,5 bar, dan komposisi 1:1,4. Percobaan yang menghasilkan nilai rata-rata ketebalan tertinggi terjadi pada percobaan ke lima belas dengan nilai ketebalan sebesar $39.9 \mu \mathrm{m}$. Ketebalan tersebut didapatkan dengan variasi variabel jarak $130 \mathrm{~mm}$, komposisi catthinner 1:1,4 dan tekanan 4,5 bar.

\section{DAFTAR PUSTAKA}

[1] Badan Pusat Statistik. 2017. Statistik Transportasi Darat. Jakarta: Badan Pusat Statistik Republik Indonesia.

[2] Argana, Sidik. 2013. Pengecatan Bodi Kendaraan Untuk SMK/MAK Kelas XI 1. Jakarta: Kementerian Pendidikan \& Kebudayaan Direktorat Jenderal Penigkatan Mutu Pendidik \& Tenaga Kependidikan.

[3] Afandi, Y. K., Arief, I. S. \& Amiadji, 2015. Analisa laju korosi pada pelat baja karbon dengan variasi ketebalan coating. Jurnal Teknik ITS, Volume 4, pp. 2337-3539.

[4] Goldschmidt, P. D. A. \& Streiberger, D. H.-J., 2007. Basic of Coating Technology.

Hannover: Vincentz Network.

[5] Hermianto, K. B. \& Utama, F. Y., 2018. Pengaruh drying process terhadap finishing top coat pada pengecatan komponen bodi kendaraan bermotor. JPTM, Volume 06, pp. 215-224.

[6] Ardyanto, W. A. \& Utama, F. Y., 2018. Rekayasa komposisi mixing solvent dan varnish terhadap kualitas hasil pengecatan menggunakan glossmeter. JPTM, Volume 07, pp. 26-33. 